\title{
Experimental and Numerical Testing of Possibilities and Limits for Applications of Phase Changed Materials in Buildings
}

\author{
Hana Charvátová ${ }^{1, *}$, Martin Zálešák ${ }^{2}$, Martin Koláček ${ }^{1}$, and Stanislav Sehnálek ${ }^{1}$ \\ ${ }^{1}$ Tomas Bata University in Zlín, Faculty of Applied Informatics, Regional Research Centre CEBIA-Tech, nám. T. G. Masaryka 5555, \\ 76001 Zlín, Czech Republic \\ ${ }^{2}$ Tomas Bata University in Zlín, Faculty of Applied Informatics, Department of Automation and Control Engineering, nám. T. G. \\ Masaryka 5555, 76001 Zlín, Czech Republic
}

\begin{abstract}
.
The paper is aimed atto a study of a possibility to use PCM (Phase Change Materials) to increase the thermal storage properties of buildings. For this purpose, both the experimental testing and computer modelling were performed. The PCM DuPont Energain panel was used for the study of its thermal technical parameters under laboratory conditions. Laboratory testing of the effect of PCM surface treatment showed a double increase in the heat transfer coefficient, but also a decrease of $17 \%$ in the time constant under given conditions. The computer modelling was used for the study of the influence of walls sheathing on the temperature comfort inside the tested room of the wooden house by its passive cooling in summer. Results of the numerical simulations proved influence of the PCM covering. But in the presented model, the PCM covering caused only a slight improvement in the thermal comfort inside the room.
\end{abstract}

\section{Introduction}

Nowadays, the buildings sector consumes about 30-40\% of the worldwide energy produced [1]. Much of this energy is used for their cooling or heating, which is associated with the high economic costs, carbon dioxide emission and subsequent natural pollution. Therefore, the issue of a thermal accumulation of buildings is currently one of the topical issues dealt with in the building industry. Reducing energy consumption in construction projects leads to a change in the insulation properties of individual structures (reduction of energy consumption), and also to the reducing energy requirements. This leads to more frequent applications of lightweight wood-based structures and thermal insulation with a basis weight of less than 200 $\mathrm{kg} / \mathrm{m}^{2}$. An application of phase change materials (PCM) as a part of building envelopes is one of the preferred methods for reducing energy intensity while achieving the desired thermal comfort for occupants inside buildings under specific climate conditions [2-5]. The main reason is the ability of PCM to store and discharge latent energy within a certain temperature range. Latent heat storage in PCM is very attractive because of its high-energy storage density and its isothermal behaviour during the phase change process. Futherrmore, the low thermal conductivity of the walls and roof reduces the heat gain at a steady state condition [6]. This stored energy can be applied both for passive heating of buildings in winter and for cooling in summer. The often solved problems connected with the PCM application in buildings are the optimal chemical composi-

*e-mail: charvatova@utb.cz tion, a form of PCM [7, 8] and their location in the buildings regarding the specific climate conditions. The phase change cycle of the PCM and their impact on indoor air and interior building surface temperatures are assessed in [9]. In this regard, our present research is focused on the study of efficiency of the covering the walls by PCM on the thermal conditions inside the buildings [4, 10]. For this purpose, both the experimental testing and computer simulations are applied for the assessment of efficiency of studied kind of PCM panels implementation on the walls in the buildings. This contribution is aimed at the theoretical and experimental study of the DuPont Energain panels which are based on PCM. It summarizes the main results obtained by laboratory testing of their thermal energy storage properties. In addition, data obtained by computer simulations show the influence of the studied PCM panels on thermal comfort in the simple model of a wooden room under the summer conditions.

\section{Basic Characteristics of PCM Incorporated in Buildings}

PCM utilizes the latent heat storage by undergoing a phase change, such as from solid to liquid state, at specific temperatures (typically referred to as melting temperatures). As indoor temperatures rise, sensible energy is stored in PCM until the melting temperature is reached. The latent heat thermal energy storage then occurs in a nearly constant temperature range while the PCM store the latent heat of fusion. The isothermal behaviour of PCM during 
the phase change process is a key factor to guarantee indoor temperature stabilization when PCM are integrated into buildings. The phase change cycle leads to the decrease in cooling and heating loads as a result of influencing the surface temperatures. In fact, the isothermal of PCM allows for better temperature control in surfaces compared to temperature fluctuations in traditionally high mass building structures with sensible storage [9].

All PCM used in building envelope applications need to go through a complete phase transition during 24-hour time periods in order to be fully effective. This is why it is critical that the temperature in the location where the PCM is installed is circulating (possibly daily) above and below the PCM functional temperature range. The PCM functional temperature range starts typically at the lowest temperature limit of the solidification process. Similarly, it ends at the highest temperature of the melting process. For well-designed PCM systems, it is crucial that this temperature range is as narrow as possible [11].

Due to a high latent heat of fusion, in summer, PCM incorporated in building walls absorb heat energy from the surroundings during the day, when the temperature is above their melting point, and release it back to the surroundings during the night, when the ambient temperature drops below melting point [12].

On the other hand, the PCM can also be used for passive heating applications. For this purpose, they can be incorporated into the building components such as floors, walls, and roofs. By absorbing the solar heat during the daytime and releasing during the night, the process of melting and solidification results in heating the indoor environment in cold seasons [13].

Except for a suitable phase transition temperature, the enthalpy content of the phase transition, the cyclic stability and the possibility of applying the material to a suitable carrier are important practical applicability parameters of PCM. PCM must not be toxic and but they must be resistant to environmental influences as are the corrosion and material leakage.

According to the chemical composition, PCM can be divided into organic and inorganic eutectic materials. The organic PCMs should be divided into materials with or without paraffins. Advantages of these materials are long cyclic stability and temperature stability without phase segregation and crystallization with negligible or no supercooling. They can absorb latent heat in the range of $170-270 \mathrm{~kJ} / \mathrm{kg}$ in the temperature between 5 and $80^{\circ} \mathrm{C}$. Therefore they are suitable for a wide range of buildings and solar installations. Organic PCMswith fatty acids, esters, alcohols and glycols which usually have the ability to accumulate large amounts of latent heat, have very low thermal conductivity, are flammable, toxic, and unstable at higher temperatures [10, 14].

Inorganic PCM are primarily salt and metal hydrates. The main advantage of salt hydrates is the low cost. Furthermore, they have high latent heat and their thermal conductivity is up to two times higher for organic PCM. However, the salt hydrates have a great influence on supercooling, non-granulating melting and poor thermal stability.
Metals are very difficult to apply PCM because of high density $[10,14]$.

The advantage of eutectics is the chemical stability and the disadvantage is the corrosion. The volume change of the melting and solidification process is about 5-10\% [10].

One of the undesirable specific undesirable of PCM is the supercooling which can occur if the PCM is subcooled below the phase transition temperature and the solidification process does not occur. Often, accumulated energy cannot be utilized, and ambient air conditions will render the entire PCM system inoperable. Commonly, night hours are used because the room air temperature drops, the PCM is cooled below the phase change temperature, and the stored energy should be easily released into the environment. However, this condition often does not occur due to subcooling. This phenomenon occurs in the PCM with salt hydrates. Therefore, nucleating agents are added to the salt hydrates to prevent the subcooling. Salt hydrates are also recommended to be applied where mechanical agitation, encapsulation or thickening agents are added to prevent salt settlement on the bottom [10].

\section{Experimental and Numerical Testing of PCM Application in Buildings}

DuPont Energain panels were used as a tested PCM for the presented study. The tested panels are laminated to aluminium protective foils, the core material is a mix of a copolymer of ethylene and a paraffin wax which provides the panel's functionality. These panels are manufactured in dimensions of $1000 \times 1198 \times 5.26 \mathrm{~mm}$ (see Figure 1(b)). The melting point is between $21-22{ }^{\circ} \mathrm{C}$. During the phase change process, the effective specific heat capacity and thermal conductivity of the PCM change significantly. The total specific heat capacity is in the range $14-30{ }^{\circ} \mathrm{C}$ is $170 \mathrm{~kJ} \cdot \mathrm{kg}^{-1}$. The thermal conductivity coefficient is $0.18 \mathrm{~W} \cdot \mathrm{m}^{-1} \cdot \mathrm{K}^{-1}$ for a solid phase and $0.14 \mathrm{~W} \cdot \mathrm{m}^{-1} \cdot \mathrm{K}^{-1}$ for a liquid phase. The dependence of specific heat capacity on the temperature of DuPont Energain is shown in Figure 1(d) [18].

\subsection{Laboratory Testing of DuPont Energain Thermal Storage Properties}

A system of storage panels was located in a laboratory inside a building of the Faculty of Applied Informatics of Tomas Bata University in Zlin. The dimensions of the study room are $7.3 \times 8.65 \times 3 \mathrm{~m}$. The glass part of the laboratory faces south. The apparatus under test consists of 2 PCM panel assemblies (see Figure 1(a)). The tested thermal system is composed of these storage panels. It consists of 12 storage plates arranged in 6 layers and two rows (see Figure $1(\mathrm{~d})$ ). Heating foils with a power of $150 \mathrm{~W} \cdot \mathrm{m}^{-2}$ and also a tube exchanger for heating the entire assembly are located between the layers.

Our experiments were focused on the assessment of the influence of thermal-technical parameters on the thermal storage properties of bguildings. During the experiments, the temperature of the panels was $35^{\circ} \mathrm{C}$ and the 

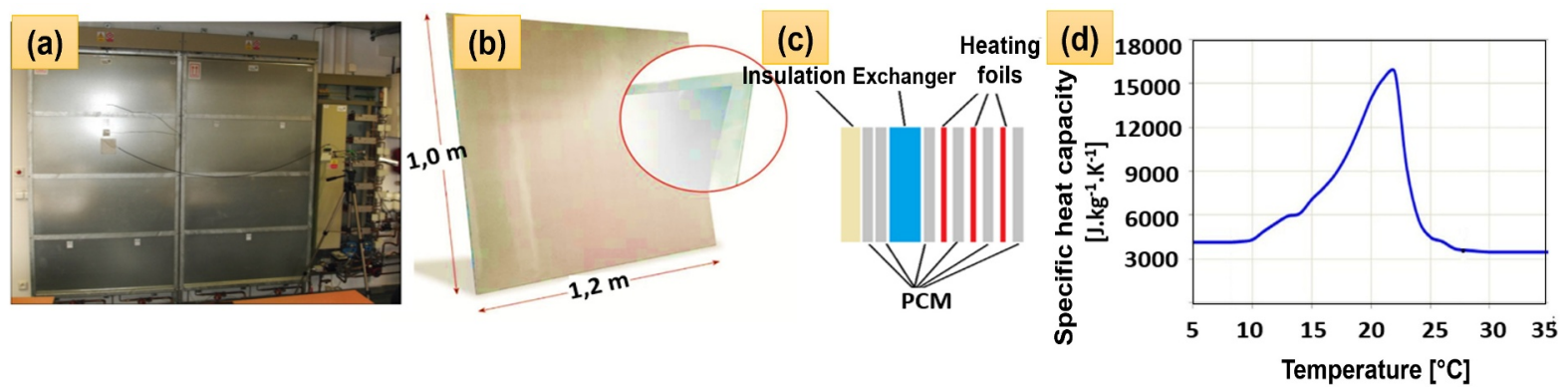

Fig. 1. Tested PCM panels: (a) accumulation panel system; b) DuPont Energain plate [18]; (c) composition of panels; d) dependence of specific heat capacity on PCM temperature.

temperature of air inside the room was of $22{ }^{\circ} \mathrm{C}$. Under these conditions results proved a time constant of 6.5 hours for tested panels. The surface heat flow on surface of the panel was $65 \mathrm{~W} \cdot \mathrm{m}^{-2}$. After the time of 85 minutes of the panels ,charging“, the measured surface temperature was in the range of $35-27{ }^{\circ} \mathrm{C}$ for 6.5 hours.

Also, surface convective parameters belong to important factors in the energy release process from the panel. The PCM sheath is made of shiny aluminium foil. This causes a very small value of the radiation component of the heat transfer coefficient due to very low emissivity. A method of surface treatment and the increase in emission value cause a noticeable release of thermal energy accompanied by a decrease of the time constant. For the experimental assessment of these properties, the panel surface was treated with black sheet paint. The heat transfer coefficient value thus doubled, but the time constant of the panel decreased by about 1 hour. This confirms that the performance of these panels depends in part on the selected surface material.

\subsection{Computer Simulation of Passive Cooling Room with Walls Covered by DuPont Energain Panels}

In this study, an influence of the PCM on thermal comfort in buildings by passive cooling in summer was tested for a model of a room which is a part of a wooden house. A geometry layout of the model is presented in Figure 2.

Walls of the room consist of two wood layers and the mineral wool was located between them (see Figure 2(b)). It was supposed that only a wall with the windows is an outdoor wall. Other walls of the room, including the ceiling and floor, are located inside the house. The PCM covers all walls of the room except the floor (see Figure 2(a)).

The Heat Transfer with Surface-to-Surface Radiation module of the COMSOL Multiphysics software was used for simulation of temperature distribution inside the room.

The studied problem has to be solved as non-stationary heat transfer using relation $(1)[15,16]$ :

$$
\nabla(-\lambda \nabla T)+\varrho c_{p} v \nabla T \varrho+c_{p} \frac{\partial T}{\partial t}=\Phi
$$

where:

$\varrho$ - material density, $\left[\mathrm{kg} \cdot \mathrm{m}^{-3}\right]$;

$c_{p}$ - specific heat capacity, $\left[\mathrm{J} \cdot \mathrm{kg}^{-1} \cdot \mathrm{K}^{-1}\right]$; $t$ - time, [s];

$\theta$ - temperature, $\left[{ }^{\circ} \mathrm{C}\right]$;

$T$ - absolute temperature, $[\mathrm{K}]$;

$v$ - fluid velocity, $\left[\mathrm{m} \cdot \mathrm{s}^{-1}\right]$

$\lambda$ - thermal conductivity, $\left[\mathrm{W} \cdot \mathrm{m}^{-1} \cdot \mathrm{K}^{-1}\right]$;

$\Phi$ - inner heat-generation rate per unit volume, $\left[\mathrm{W} \cdot \mathrm{m}^{-3}\right]$.

The external radiation source condition was defined via the Solar Position option. For this purpose, the direction and intensity of the sun's incident radiation based on the latitude and longitude position on Earth were inserted as a boundary condition.

The boundary condition for the heat flow rate $q$ was defined as [17]

$q_{s}=h_{t}\left(\theta_{a}-\theta_{s}\right)+h_{r}\left(\theta_{r}-\theta_{s}\right)+\sum_{j} a_{j} E_{j}-\varepsilon\left(\sigma T_{e}^{4}-E_{a t}\right)$

where:

$q_{s}$ - heat flow rate at the surface, $\left[\mathrm{W} \cdot \mathrm{m}^{-2}\right]$;

$h_{t}$ - heat transfer coefficient, $\left[\mathrm{W} \cdot \mathrm{m}^{-2} \cdot \mathrm{K}^{-1}\right]$;

$h_{r}$ - surface coefficient of radiant heat transfer, $\left[\mathrm{W} \cdot \mathrm{m}^{-2} \cdot \mathrm{K}^{-1}\right]$

$\theta_{a}$ - air temperature near the surface, $\left[{ }^{\circ} \mathrm{C}\right]$;

$\theta_{s}$ - surface temperature, $\left[{ }^{\circ} \mathrm{C}\right]$;

$\theta_{r}$ - mean radiant temperature perceived by the surface, $\left[{ }^{\mathrm{o}} \mathrm{C}\right]$;

$T_{e}$ - outdoor temperature, $[\mathrm{K}]$;

$a_{j}$ - absorptivity of the surface for radiation of source $j$, [-];

$E_{j}$ - irradiance of radiant source $j,\left[\mathrm{~W} \cdot \mathrm{m}^{-2}\right]$;

$\varepsilon$ - surface emissivity, [-];

$\sigma$ - Stephan-Boltzmann constant, $\left[\mathrm{W} \cdot \mathrm{m}^{-2} \cdot \mathrm{K}^{-4}\right]$;

$E_{a t}$ - atmospheric radiation, $\left[\mathrm{W} \cdot \mathrm{m}^{-2}\right]$.

The PCM was modeled by insertion of a condition for Heat Transfer with Phase Change which is a part of the Heat Transfer Module. For simplification of the simulation, the density, specific heat capacity and thermal conductivity of the PCM were inserted as the mean values in a temperature range of the PCM phase change between a solid and liquid phase. 
Table 1. Properties of materials of the studied house.

\begin{tabular}{lcccc}
\hline Material & $\begin{array}{c}\text { Thermal } \\
\text { conductivity } \\
{\left[\mathrm{W} \cdot \mathrm{m}^{-1} \cdot \mathrm{K}^{-1}\right]}\end{array}$ & $\begin{array}{c}\text { Density } \\
{\left[\mathrm{kg} \cdot \mathrm{m}^{-3}\right]}\end{array}$ & $\begin{array}{c}\text { Specific } \\
\text { heat capacity } \\
{\left[\mathrm{J} \cdot \mathrm{kg}^{-1} \cdot \mathrm{K}^{-1}\right]}\end{array}$ & $\begin{array}{c}\text { Emissivity } \\
{[1]}\end{array}$ \\
\hline Wood & 0.18 & 400 & 2510 & 0.89 \\
Mineral wool & 0.064 & 200 & 880 & - \\
Glass & 0.76 & 2600 & 840 & 0.96 \\
PCM & 0.16 & 800 & 9000 & 0.99 \\
\hline
\end{tabular}

(a)

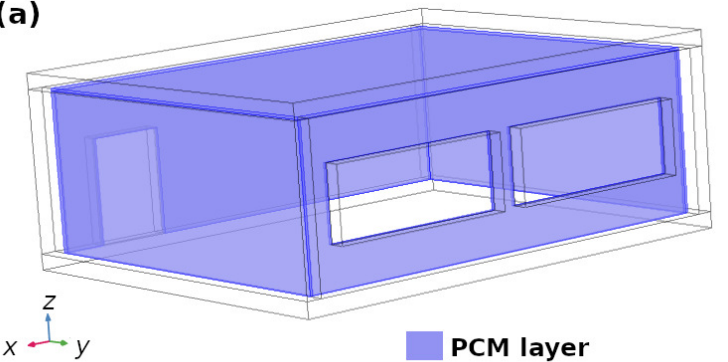

(b)

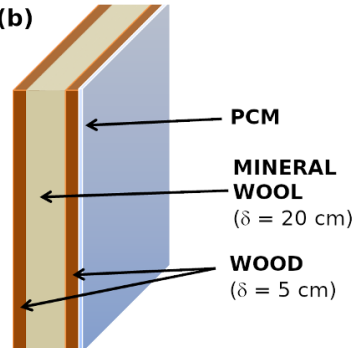

Fig. 2. Geometric layout of the studied model (a) 3D sketch of the room and (b) structure of the PCM-covered walls.

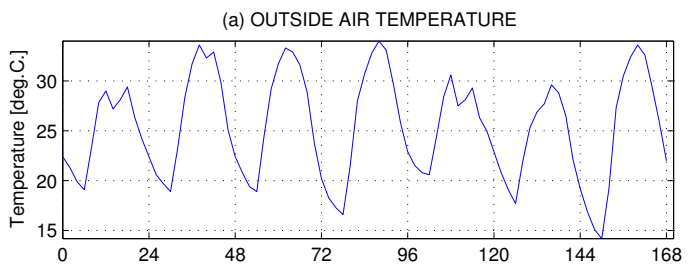

(b) SOLAR RADIATION

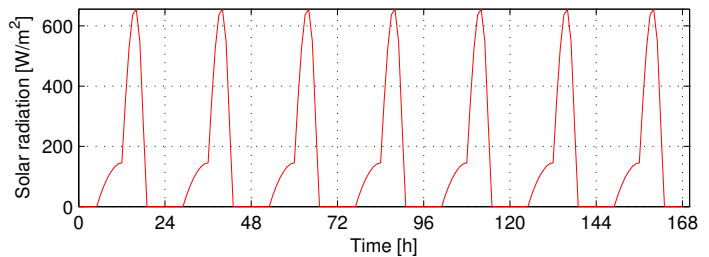

Fig. 3. The temperature of the air outside the building and the solar radiation — data used as the boundary conditions for the tested model.

\subsubsection{Simulation Setup}

The aim of simulations was to evaluate the influence of the PCM layers covering the walls on the passive cooling the studied room in summer under the external temperature and solar radiation conditions shown in Figure 3.

The supposed house location is in Central Europe with geographic coordinates of the latitude $49.2240^{\circ} \mathrm{N}$ and longitude $17.6630^{\circ} \mathrm{E}$. The time zone with Coordinated Universal Time (UTC) is +2 hours under the tested summer conditions presented in Figure 3. In Figure 3(a) is shown the temperature of the air outside the building [21]. It includes data measured in the studied region in the first week of August. In Figure 3(b) is depicted the solar radiation acting on the back wall of the studied room during thesimulation. The data were used from the Czech technical standard [19]. Further conditions, geometry and material properties of the studied model include:
- Room dimensions: length $8.7 \mathrm{~m}$, width $7.2 \mathrm{~m}$, height $3 \mathrm{~m}$.

- Structure of the walls of the room is depicted in Figure 2. They consist of two wood layers and the mineral wool is placed between them. The thickness of the wood layers is $5 \mathrm{~cm}$. The thickness of the mineral wool is $20 \mathrm{~cm}$.

- Physical properties of the geometrical elements of the simulated room are listed in Table 1.

- Initial temperature of the air inside the tested room $24^{\circ} \mathrm{C}$.

- Initial temperature of the room walls $24.5^{\circ} \mathrm{C}$.

- Temperature of air in the adjoining rooms $25^{\circ} \mathrm{C}$.

- Velocity of the airflow inside the room $0.1 \mathrm{~m} . \mathrm{s}^{-1}$.

- Heat transfer coefficient inside the house $8 \mathrm{~W} \cdot \mathrm{m}^{-2} \cdot \mathrm{K}^{-1}$.

- Heat transfer coefficient outside the house $25 \mathrm{~W} \cdot \mathrm{m}^{-2} \cdot \mathrm{K}^{-1}$.

- Area of the windows takes $46 \%$ of the back wall area.

The PCM was implemented as a layer of $15-30 \mathrm{~mm}$ thickness, which covers all the peripheral walls and ceiling inside the studied room as is shown in Figure 2. Its supposed properties are:

- Phase change temperature between solid and liquid phase $20^{\circ} \mathrm{C}$.

- Transition interval between solid and liquid phase $4{ }^{\circ} \mathrm{C}$.

- Latent heat from solid and liquid phase $200 \mathrm{~kJ} / \mathrm{kg}$.

- Density, specific heat capacity and thermal conductivity of the PCM were inserted as their mean values in the given temperature range. Their values are listed in Table 1 . 


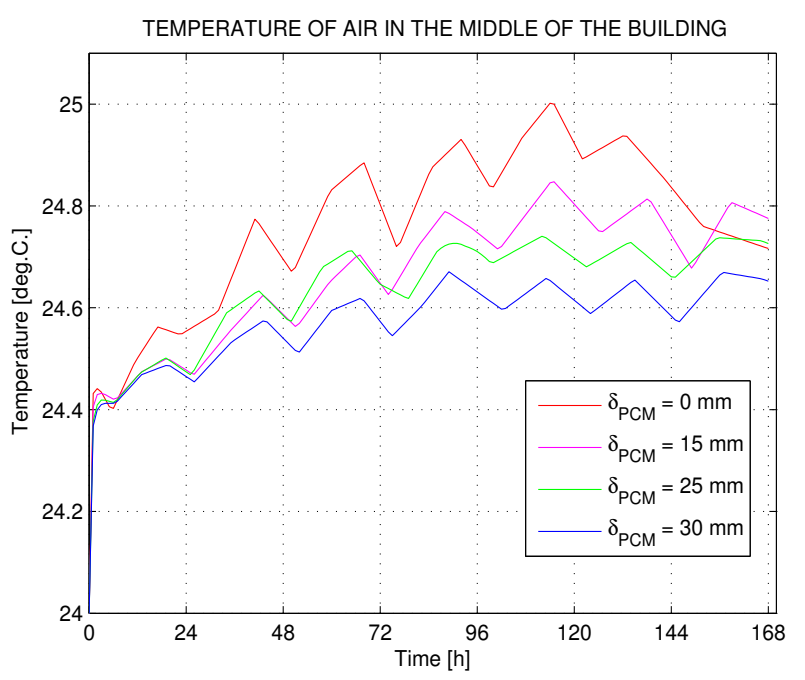

Fig. 4. Time evolution of the air temperature in the centre of the room with regard to the PCM thickness. The red line indicates the time evolution of the air temperature in the building without the PCM coverage.

\subsubsection{Results of Simulation}

Results of simulations are shown in Figures 4 - 5. Figure 4 is presents a time evolution of the air temperature in the centre of the room with regard to the PCM thickness. The red line indicates the time evolution in the building without the PCM coverage. The other lines represent the room covered by the PCM of a thickness of $15 \mathrm{~mm}, 25 \mathrm{~mm}, 30$ $\mathrm{mm}$.

In this experiment, the PCM covering caused only a slight improvement in the thermal comfort inside the room. The maximal temperature difference between the room covered by $30 \mathrm{~mm}$ PCM layer and the room without PCM was about $0.35{ }^{\circ} \mathrm{C}$ under given conditions. This can be caused by many factors as are boundary conditions setup, using inappropriate PCM for given climate conditions or improper PCM location. In this regard, authors [20] suggest the optimal phase change temperature 1.1-3.3 ${ }^{\circ} \mathrm{C}$ higher than the lower limit of thermal comfort in a passive solar room range.

But accuracy of the results is also affected by the setting of the used mesh quality for numerical computing in the studied model [16]. The mesh quality is limited by the used computer capability, which can also cause slight inaccuracies in the results achieved. A free tetrahedral mesh specified by a matrix of about 4,200,000 elements (degrees of freedom) was used to solve the finite element problem in the model environment.

Figure 5 is depicts the time evolution of the surface temperature in the room with PCM of $30 \mathrm{~mm}$ thickness. The values are read at a distance of $1.5 \mathrm{~m}$ from the floor for all the peripheral walls and at the centre of the room when reading the surface temperature of the ceiling. Daytime variations in temperature are evident on the surface of all walls.

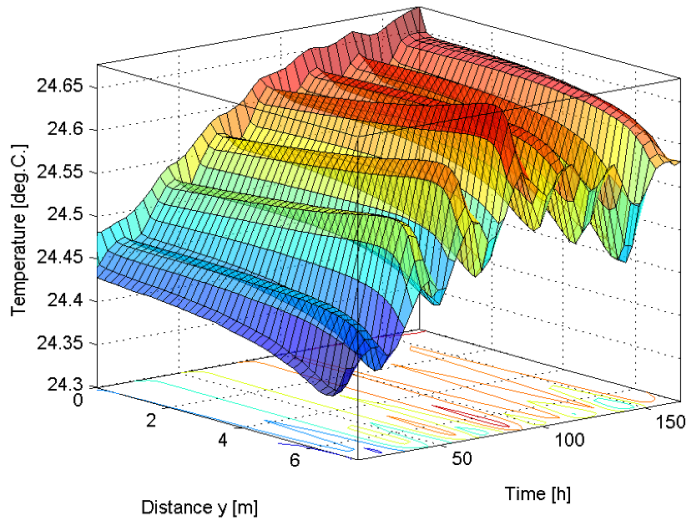

(a) Left wall

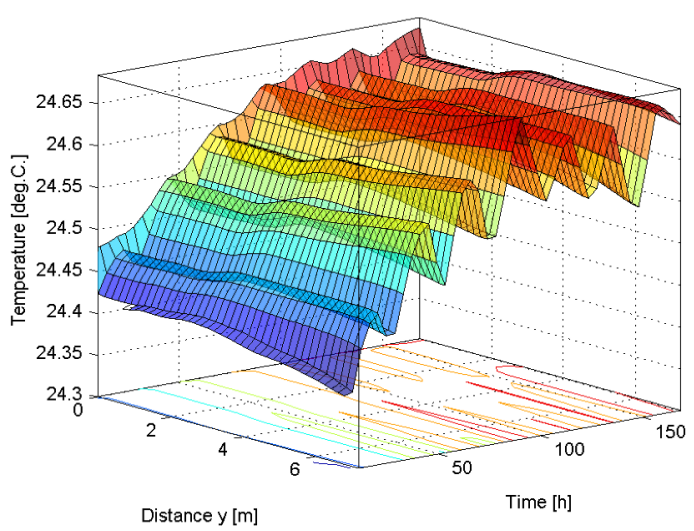

(b) Ceiling

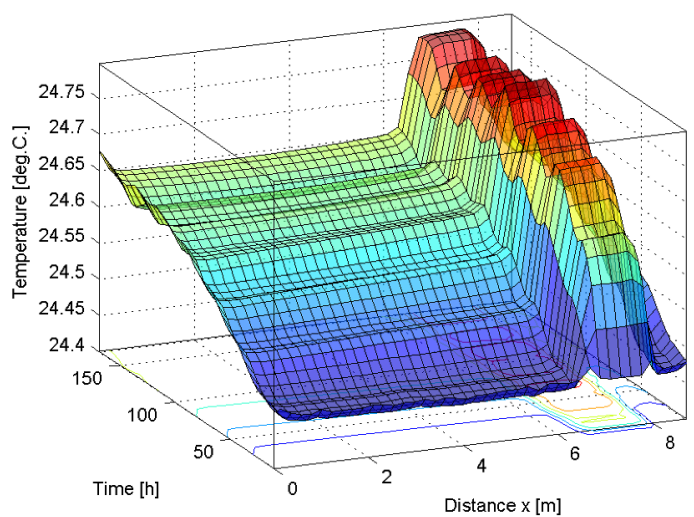

(c) Front wall

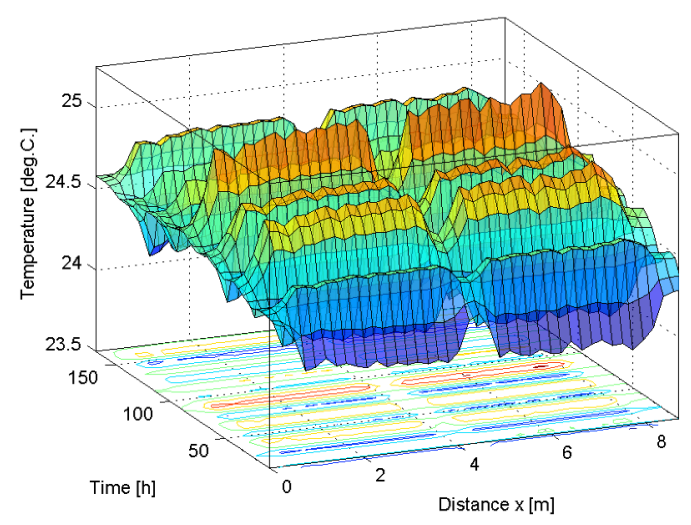

(d) Back wall

Fig. 5. Time evolution of the surface temperatures. 
Figures 5(a,c) present temperature evolution it the left wall and in the ceiling. In these graphics, the coordinate y indicates distance in a door-to-window direction (see Figure 2(a)). In Figure 5(c) is shown the temperature evolution in the front wall (i.e in the wall with the door). It is evident temperature increase in the distance $y$ about 6.2 $8 \mathrm{~m}$ which represents the surface of the door which is not covered by the PCM layer.

Similarly, in Figure 5(d) is depicted the temperature evolution in the back wall (i.e in the outside wall with the windows). It is evident temperature increase in the distance $y$ which represents the surface of the windows that are not covered by the PCM.

\section{Conclusion}

The presented results proved the tested DuPont Energain as a suitable PCM which can improve thermal storage properties of buildings.

The experimental testing was focused on an assessment of a time constant of the studied PCM panel under laboratory conditions. Testing of the effect of PCM surface treatment on the heat transfer rate showed a double increase in the heat transfer coefficient, but the time constant decreased by $17 \%$ under given laboratory conditions.

The results of computer simulations showed a slight improvement in thermal comfort inside the room of the wooden building in summer due to the coverage of its inner walls with a layer of PCM material. Under tested conditions, the maximal temperature difference between the room covered with a $3 \mathrm{~cm}$ thick PCM layer and the room without PCM was about $0.35^{\circ} \mathrm{C}$.

We expect future work to be focused on both the experimental testing and computer simulations for other boundary conditions as well as for other kinds of constructions, PCM materials and their location inside the building.

\section{Acknowledgement}

This work was supported by the Ministry of Education, Youth and Sports of the Czech Republic within the National Sustainability Programme project No. LO1303 (MSMT-7778/2014).

\section{References}

[1] M.T. Plytaria, E. Bellos, C. Tzivanidis, K.A. Antonopoulos, Energy Conversion \& Management 188, 40 (2019)
[2] M. Saffari, A. De Gracia, S. Ushak, L.F. Cabeza, Renewable \& Sustainable Energy Reviews 80, 1239 (2017)

[3] C.A. Konstantinidou, W. Lang, A.M. Papadopoulos, International Journal of Energy Research 42, 3030 (2018)

[4] X. Jin, D. Shi, M. Medina, X. Shi, X. Zhou, X. Zhang, Journal of Thermal Analysis \& Calorimetry 129, 1767 (2017)

[5] F. Herbinger, L. Desgrosseilliers, D. Groulx, in Proceedings of the 2014 COMSOL Conference (Boston, MA, 2014)

[6] A. Mannivannan, M. Jaffarsathiq ALI, Sadhana 40, 2381 (2015)

[7] M. Alam, P.X. Zou, J. Sanjayan, S. Ramakrishnan, Applied Energy 238, 1582 (2019)

[8] K.O. Lee, M.A. Medina, X. Sun, X. Jin, Solar Energy 163, 113 (2018)

[9] U. Berardi, S. Soudian, Energy \& Buildings 185, 180 (2019)

[10] M. Kolacek, Utilization of thermal storage materials PCMs in specific applications of environmental engineering (in Czech) (Thesis, Tomas Bata University in Zlin, 2018)

[11] J. Kośny, E. Kossecka, ASHRAE Transactions 119, 1 (2013)

[12] N. Sharifi, A. Shaikh, A. Sakulich, in Proceedings of the 2015 COMSOL Conference (Boston, MA, 2015)

[13] A. Kasaeian, L. bahrami, F. Pourfayaz, E. Khodabandeh, W.M. Yan, Energy \& Buildings 154, 96 (2017)

[14] M. Saffari, L.F. Cabeza, A. de Gracia, C. Fernández, Applied Energy 202, 420 (2017)

[15] Heat Transfer Module User's Guide (COMSOL, 2017)

[16] H. Charvatova, A. Prochazka, M. Zalesak, Energies $11(2018)$

[17] Z. Huijbregts, J. Schijndel, J. Schellen, K. Keune, M. Hommes, in Proceedings of the European COMSOL Conference (Technische Universiteit Eindhoven, Cambridge, UK, 2014)

[18] J. Gilbert, U. Koster DuPont Energain PCM Guidebook (DuPont: Wilmington, DE, USA, 2010)

[19] CSN 73 0540-3. Thermal protection of buildings Part 3: Design value quantities (in Czech) (Office for Standards, Metrology and Testing. Prague, 2005)

[20] F. Jiang, X. Wang, Y. Zhang, Energy Conversion and Management 52, 2437 (2011)

[21] In-pocasi. Weather archive, climate of the Czech Republic. Available online: https://www.inpocasi.cz/archiv/ (accessed on 29 April 2019) 